\title{
Impact of surface coupling grids on tropical cyclone extremes in high-resolution atmospheric simulations
}

\author{
Colin M. Zarzycki ${ }^{1}$, Kevin A. Reed $^{2}$, Julio T. Bacmeister ${ }^{1}$, Anthony P. Craig ${ }^{1}$, Susan C. Bates ${ }^{1}$, and \\ Nan A. Rosenbloom ${ }^{1}$ \\ ${ }^{1}$ National Center for Atmospheric Research, Boulder, Colorado, USA \\ ${ }^{2}$ School of Marine and Atmospheric Sciences, State University of New York at Stony Brook, Stony Brook, New York, USA \\ Correspondence to: Colin M. Zarzycki (zarzycki@ucar.edu)
}

Received: 19 August 2015 - Published in Geosci. Model Dev. Discuss.: 11 September 2015

Revised: 1 February 2016 - Accepted: 8 February 2016 - Published: 25 February 2016

\begin{abstract}
This paper discusses the sensitivity of tropical cyclone climatology to surface coupling strategy in highresolution configurations of the Community Earth System Model. Using two supported model setups, we demonstrate that the choice of grid on which the lowest model level wind stress and surface fluxes are computed may lead to differences in cyclone strength in multi-decadal climate simulations, particularly for the most intense cyclones. Using a deterministic framework, we show that when these surface quantities are calculated on an ocean grid that is coarser than the atmosphere, the computed frictional stress is misaligned with wind vectors in individual atmospheric grid cells. This reduces the effective surface drag, and results in more intense cyclones when compared to a model configuration where the ocean and atmosphere are of equivalent resolution. Our results demonstrate that the choice of computation grid for atmosphere-ocean interactions is non-negligible when considering climate extremes at high horizontal resolution, especially when model components are on highly disparate grids.
\end{abstract}

\section{Introduction}

The use of general circulation models (GCMs) to evaluate global tropical cyclone (TC) characteristics in current and future climate has grown considerably over the last decade. It has been shown that GCMs can model TCs at horizontal resolutions of approximately $100 \mathrm{~km}$ grid spacing, albeit with limitations (e.g., Bengtsson et al., 2007; Knutson et al., 2010; Strachan et al., 2013). As GCMs have advanced to even higher horizontal resolutions (i.e., $\leq 50 \mathrm{~km}$ ) the sim- ulated climatology of tropical cyclones has improved greatly (e.g., Oouchi et al., 2006; Zhao et al., 2009; Murakami et al., 2012; Manganello et al., 2012; Satoh et al., 2012; Bacmeister et al., 2014; Wehner et al., 2014; Reed et al., 2015). Furthermore, the use of variable-resolution GCMs has shown to be useful for the study of regional TC climatologies at reduced computational cost compared to equivalent global high-resolution simulations, providing further resources capable of pushing climate simulations to finer grid spacings (Zarzycki et al., 2014a; Zarzycki and Jablonowski, 2014).

Recently, intercomparisons have shown that the range of simulated TC climatologies across different climate models can be large (Camargo, 2013; Walsh et al., 2015). It has also been shown that, within individual GCMs, TC characteristics can vary greatly depending on model design choices. Various studies have documented the large uncertainty in TC simulations due to the choice of individual subgrid parameterizations, such as cumulus parameterizations (e.g., Kim et al., 2012; Reed and Jablonowski, 2011a; Lim et al., 2014), while others have focused on differences due to changes in entire parameterization suites (Reed and Jablonowski, 2011b; Bacmeister et al., 2014). The dynamical core, the main fluid flow component of a GCM, has also been shown to be an important source of uncertainty for TC simulations, though less widely documented (Reed and Jablonowski, 2012; Zhao et al., 2012; Reed et al., 2015).

In this paper, we describe another mechanism through which simulated TC properties are influenced by model design choices, in particular, the manner in which the ocean and atmosphere are coupled within the climate system. Specifically, we will utilize the Community Atmosphere Model ver- 
sion 5 (CAM5), within the Community Earth System Model (CESM), to explore the impact of two different strategies for coupling to a prescribed ocean. CAM5 has shown increasing ability to model tropical cyclones at high horizontal resolutions of $0.25^{\circ}$ (Bacmeister et al., 2014; Zarzycki and Jablonowski, 2014; Wehner et al., 2014, 2015; Reed et al., 2015), and a similar model setup will be used for part of this study.

The remainder of the paper is organized as follows. Section 2 provides an introduction to the modeling system used in this study and explains how coupling between the atmosphere and ocean is treated. Section 3 investigates the impact on multi-year climate simulations while Sect. 4 details the sensitivity of TCs to the ocean grid using a deterministic forecast framework. Section 5 discusses the results and offers further insight into their implications.

\section{Model description}

\subsection{Community Earth System Model}

In this paper, we utilize CESM, which is a community climate model allowing for atmospheric simulations to be coupled to land, ocean, and ice models (Hurrell et al., 2013). The atmospheric component, CAM5 (Neale et al., 2012), is configured with the Spectral Element (SE) dynamical core. $\mathrm{SE}$ is the newest dynamical core available in CAM5 and is based upon continuous Galerkin spectral finite elements applied on a cubed-sphere grid (Taylor et al., 1997; Thomas and Loft, 2005; Taylor and Fournier, 2010). In addition to attractive conservation characteristics (Taylor, 2011), CAMSE has shown appealing scaling properties since atmospheric primitive equations are solved locally on individual elements (Dennis et al., 2012; Evans et al., 2013). The land model is the Community Land Model (CLM) version 4.0 run in satellite phenology (SP) mode (Oleson et al., 2010). While CESM also allows for coupling to dynamic ocean and ice models, all of the simulations here utilize prescribed sea surface temperatures (SSTs) and ice cover concentrations. Using data forcing for the ocean and ice models is a commonly used configuration that minimizes the computational cost associated with high-resolution atmospheric modeling (Walsh et al., 2015). In the default CESM configuration, prescribed SST and ice data at $1^{\circ} \times 1^{\circ}$ resolution are internally interpolated to the particular data ocean and ice components. Since these components therefore only require a data stream, their cost is negligible compared to the dynamical atmospheric model.

\subsection{Coupling within CESM}

When all earth system model components operate on identical grids, vertical coupling (such as between the ocean surface and lowest level of the atmosphere) is straightforward. However, since components are generally not integrated on the same spatial grid, CPL7 is used to couple these com- ponents to one another within the CESM framework (Craig et al., 2012). The coupler utilizes remapping weights to regrid quantities which are needed across model components. Figure 1 provides a schematic of the standard coupling process when differences exist between, for example, the resolution of the atmosphere and ocean grids in CESM. In this case, the atmospheric grid (red) is of finer resolution. Historically, this has not been the case, with the surface model (land, ocean, ice) grids being finer than their (more computationally intensive) atmospheric counterparts. As computing capabilities improve, and smaller atmospheric grid spacings become more common in simulations utilizing prescribed SSTs and ice data forcing, it is no longer typical for the ocean resolution to be similar or finer in resolution in such setups. Therefore, having the atmospheric grid be the finest in the climate system is currently the default setup for many high-resolution configurations in CESM.

Atmospheric variables, such as winds (black vectors; taken here to approximate the flow associated with a Northern Hemisphere tropical cyclone), are computed on the atmospheric grid (Fig. 1a). Generally, CESM has computed atmosphere-ocean fluxes on the ocean grid. Therefore, when coupling is required, these atmospheric values are then conservatively remapped to the ocean grid (blue) (Fig. 1b). Surface momentum stress ( $\tau$, gray vectors) and sensible and latent heat fluxes (not shown) are calculated on the ocean grid using the remapped atmospheric quantities (Fig. 1c). These calculated values are then remapped back to the atmospheric grid using either conservative remapping or bilinear interpolation (Fig. 1d), where they are used by the atmospheric component of the model for integration (Fig. 1e). While the exact techniques that various GCMs use to couple model components are not identical, this general framework of mapping required quantities across grids is commonly used.

\section{Climate simulations}

We first compare TC statistics in two multi-decadal climate simulations using $0.25^{\circ}(\sim 28 \mathrm{~km}$, denoted as ne120 on the spectral element cubed-sphere grid) resolution for the atmosphere. Both simulations follow Atmospheric Model Intercomparison Project (AMIP) protocols (Gates, 1992) and are coupled to CLM on a standard latitude-longitude grid with an equivalent resolution of approximately $0.25^{\circ}$. The first simulation uses prescribed ocean and sea ice conditions applied on a grid where the polar point is displaced over Greenland, which is at approximately $1^{\circ}$ horizontal resolution (ne120_gx1v6). This is coarser than both the atmosphere and land models. The second simulation is identical to the first, except the ocean and ice conditions are applied on the same $0.25^{\circ}$ (ne120) grid as the atmosphere and land (ne120_ne120). For both simulations, all atmosphere-ocean coupling calculations are carried out on the ocean grid. We note that these are both supported, "out of the box", grid con- 

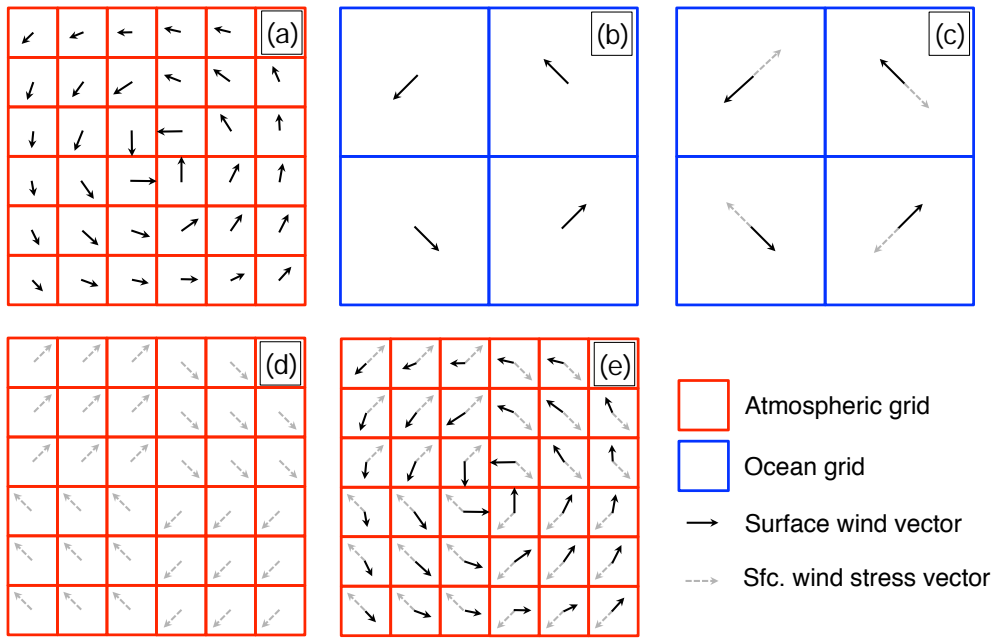

Figure 1. Coupling procedure in CESM. Red (blue) boxes indicate atmospheric (ocean) grid cells. Black (gray) solid (dashed) vectors show surface wind (wind stress) vectors. Surface winds are taken from the atmospheric grid (a) and mapped to the ocean grid (b). Calculations of surface drag are carried out on the ocean grid (c) with surface wind stress vectors being remapped back to the atmosphere grid (d) for use in atmospheric integration at the next time step (e). Surface heat fluxes are calculated in a similar manner.

figurations in CESM. SSTs and ice coverage are applied using the monthly $1^{\circ}$ Hadley Centre sea ice and sea surface temperature data set (HadISST; Hurrell et al., 2008). While the ocean and ice models may operate on the $0.25^{\circ}$ grid, all data are interpolated from the same $1^{\circ}$ data set. Therefore, the higher-resolution ocean grid does not provide more spatial structure in surface forcing, isolating the effect of solely the resolution of the coupling calculations.

Both simulations are integrated from 1980 to 2005 . Taylor statistics for the 1980-2000 global-mean quantities for sea-level pressure (PSL), total precipitable water (TMQ), total precipitation rate (PRECT), $200 \mathrm{hPa}$ zonal wind (U200), $850 \mathrm{hPa}$ zonal wind (U850), $600 \mathrm{hPa}$ relative humidity (RH600), and $500 \mathrm{hPa}$ temperature (T500) are shown in Fig. 2. The two simulations are compared to observational data sets including NCEP (Kalnay et al., 1996) (PSL, U200, U850, RH600, T500), MERRA (Rienecker et al., 2011) (TMQ), and TRMM (Huffman et al., 2007) (PRECT). The absolute distance from the origin (lower left) represents the magnitude of the spatial variability within the domain (as measured by normalized standard deviation) while the spatial correlation is plotted as the radial angle between the model marker and the origin. A comprehensive discussion of Taylor diagram analysis can be found in Taylor (2001). Red dots highlight the climatology of the ne120_ne120 simulation while blue dots show the same for the ne120_gx1v6 simulation. This analysis is only concerned with the relative difference between the two simulations and, therefore, whether or not mean climatology is impacted by choice of coupling grid. A thorough analysis to understand why each parameter is modeled with their particular skill in CAM5 itself is beyond the scope of this paper. We do note, however, that the results are consistent with skill scores reported in previous

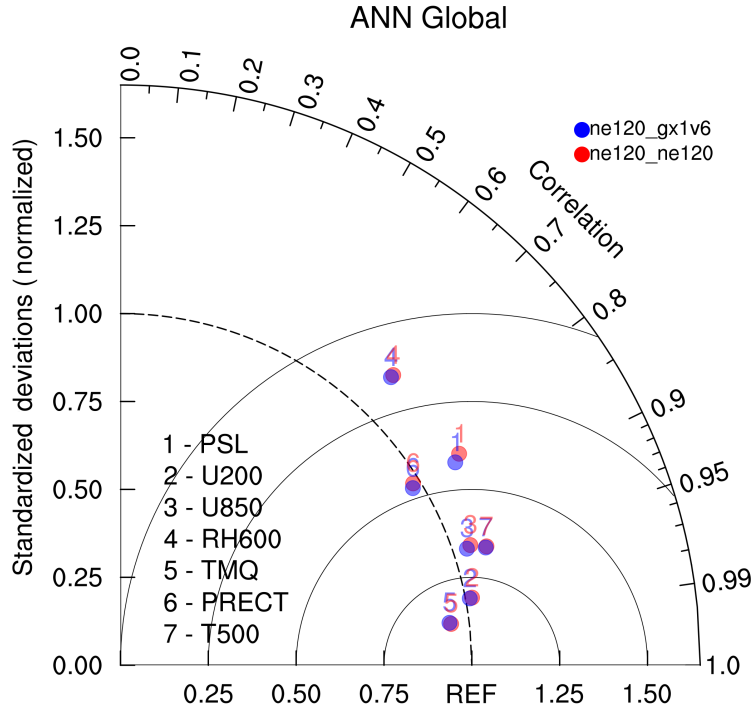

Figure 2. Taylor diagram for globally and annually averaged climate statistics. Blue circles represent the results from AMIP simulation coupled to $1^{\circ}$ ocean grid (ne120_gx1v6) and red circles represent the same for simulation using $0.25^{\circ}$ ocean grid (ne120_ne120). See text for description of the diagram and explanation of abbreviations.

CAM5 modeling studies, such as Bacmeister et al. (2014) (their Figs. 2 and 3) and Zarzycki et al. (2015) (their Fig. 9).

The most notable result from assessing this skill is the two simulations are highly similar in a global climatological sense. All markers representing the ne120_gx1v6 simulation overlap with their corresponding variable from the ne120_ne120 simulation. The occurrence of this overlap 
highlights that the mean climate state is not impacted by choice of coupling strategy in the climate simulations.

However, while the mean climatologies of the two simulations are essentially identical, notable differences arise when comparing TC statistics between the two simulations. TCs are objectively tracked in model output using the method first outlined in Vitart et al. (1997) and updated by Knutson et al. (2007). The version of the TC tracker applied in this study utilizes 3-hourly model output from the atmospheric component and is described in detail in Zhao et al. (2009). Previous work using this technique to find TCs in CAM/CESM output has produced a reasonable storm climatology, both spatially and in terms of storm intensity (Reed et al., 2015). For the tracker, all data are regridded from the CAM-SE ne120 cubed-sphere grid to a $0.25^{\circ}$ latitude-longitude grid as in Reed et al. (2015). Surface winds (taken to be at a height of $10 \mathrm{~m}$ ) are approximated from the lowermost model level winds $(\approx 60 \mathrm{~m})$ and a logarithmic law as described in Zarzycki and Jablonowski (2014).

Table 1 displays storm counts for all TCs, storms that reach hurricane strength $\left(>33 \mathrm{~m} \mathrm{~s}^{-1}\right)$ and storms that reach major hurricane strength $\left(>59 \mathrm{~m} \mathrm{~s}^{-1}\right)$ on the Saffir-Simpson scale (Simpson, 1974) (major hurricane defined here as categories 4 and 5) for each simulation for 1980 through 2005. Observations from the International Best Track Archive for Climate Stewardship (IBTrACS; Knapp et al., 2010) for the same time period are provided as a reference. Both simulations produce roughly the same frequency of total storms, with the ne120_ne120 configuration only producing approximately $4 \%$ more TCs annually. The same relationship holds true for mean storm lifetime. Spatial plots of TC track density also show no discernible difference (not shown). However, despite this, the simulation coupled to the lower-resolution ocean (ne120_gx1v6) produces $10 \%$ more hurricanes and nearly 3 times the amount of major hurricanes when compared to the simulation with the higher-resolution coupling. Given that the total number of storms is roughly equivalent between the two configurations, this signifies a shift in the overall intensity distribution towards stronger TCs in the ne120_gx1v6 setup. This is further corroborated by the mean TC precipitation rate (integrated over a $2 \times 2^{\circ}$ domain over the TC center for all storms), which is approximately $2 \%$ higher using the ne120_gx1v6 configuration (not shown).

To explore this further, Fig. 3 displays the minimum surface pressure versus maximum $10 \mathrm{~m}$ wind speed relationship for TCs in each simulation with a quadratic least squares fit shown as a solid line. IBTrACS observations are again included as a reference. To be consistent with the TC tracker, only storms that reach tropical storm strength in their lifetime are used. At low wind speeds (i.e., $<40 \mathrm{~m} \mathrm{~s}^{-1}$ ) the relationship between the minimum surface pressure and maximum wind speed for the two model simulations and observations compares well. However, at larger wind speeds the relationship between the two simulations diverges, consistent with the differences in TC counts in Table 1. In particular, the

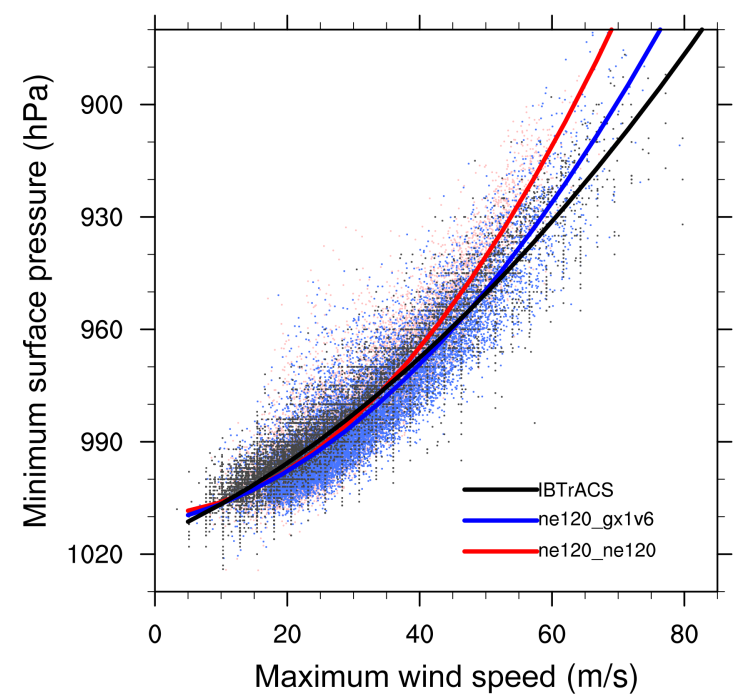

Figure 3. Storm minimum surface pressure vs. maximum $10 \mathrm{~m}$ wind speed relationship with quadratic least squares fit (solid lines) for the CAM5 simulations and IBTrACS observations from 1980 to 2005. Note that 3-hourly output is used for the model simulations, while the IBTrACS data are 6-hourly.

ne120_gx1v6 simulation produces greater wind speeds at a given minimum pressure than the ne120_ne120 simulation, suggesting the ocean coupling resolution impact on tropical cyclone intensity is non-negligible, especially with respect to intense TCs.

Figure 4 shows the number of annual $10 \mathrm{~m}$ TC wind exceedances in the 3-hourly model output for both category 3 and category 4 storm thresholds. These represent two of the most intense classifications of tropical cyclones, with maximum $10 \mathrm{~m}$ winds surpassing 50 and $59 \mathrm{~m} \mathrm{~s}^{-1}$, respectively. The blue curve with open markers indicates the number of $3 \mathrm{~h}$ samples within the TC trajectories which surpass each threshold in the simulation using the $1^{\circ}$ ocean grid (ne120_gx1v6). The red curve with filled markers represents the same for the simulation with the $0.25^{\circ}$ ocean grid (ne120_ne120). From the left panel, we see that for all years (except 1985 and 1988), the simulation coupled to the coarser ocean grid produces a significantly greater frequency of category 3 level winds, with the average number of annual instances being approximately 6 times higher than when using the high-resolution ocean grid. This behavior is even more pronounced in the right panel, where the ne120_gx1v6 simulation averages approximately 10 instances of category 4 level winds per year. However, this threshold is not exceeded at any point during the 25-year sample in the ne120_ne120 simulation. 
Table 1. Annual frequency of global tropical cyclones that reach tropical storm (cat. 0-5), hurricane (cat. 1-5), and major hurricane (cat. 4-5) strength the CAM5 simulations and IBTrACS observations for the time period of 1980 to 2005. The average storm lifetime is also included. The standard deviation for each variable over the sampling period is used as an estimate of uncertainty.

\begin{tabular}{lllll}
\hline Simulation & Total storms (no./year) & Avg. storm lifetime $(\mathrm{h})$ & Hurricanes (no./year) & Major hurricanes (no./year) \\
\hline IBTrACS & $91.6 \pm 8.5$ & $170.2 \pm 93.2$ & $47.1 \pm 5.5$ & $10.7 \pm 3.3$ \\
ne120_gx1v6 & $70.1 \pm 9.0$ & $175.4 \pm 97.3$ & $55.5 \pm 7.7$ & $12.5 \pm 3.4$ \\
ne120_ne120 & $73.2 \pm 10.5$ & $179.7 \pm 101.9$ & $50.3 \pm 8.2$ & $4.2 \pm 1.9$ \\
\hline
\end{tabular}
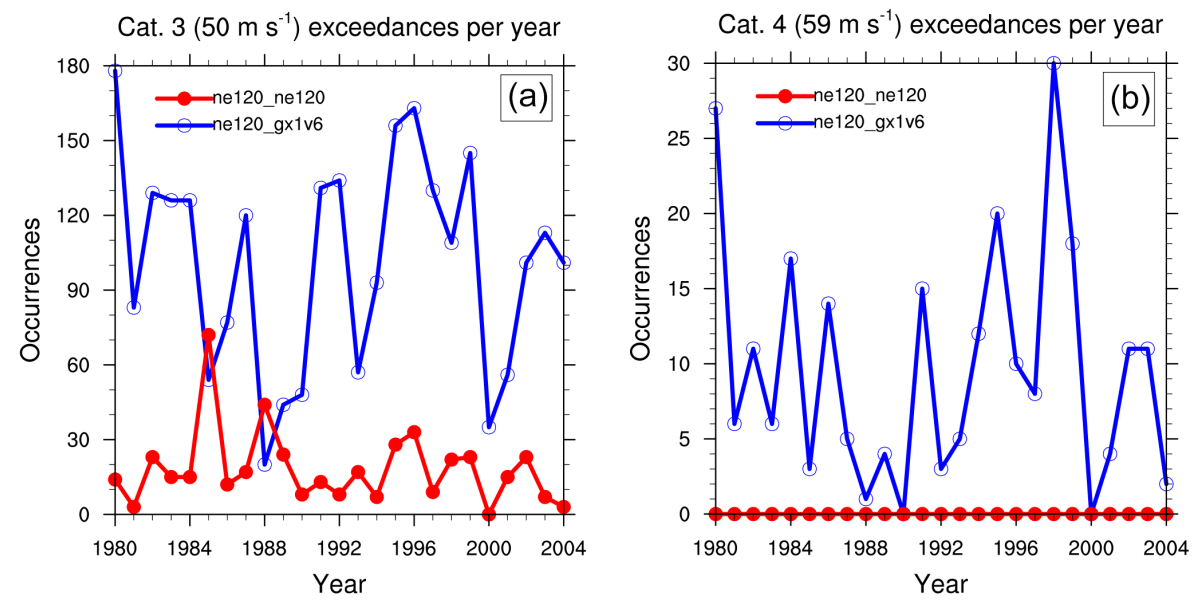

Figure 4. Number of TC surface wind instances exceeding category 3 and category 4 wind thresholds for AMIP simulation coupled to $1^{\circ}$ ocean grid (ne120_gx1v6) and $0.25^{\circ}$ ocean grid (ne120_ne120). Instances are calculated using 3-hourly TC trajectories.

\section{Deterministic simulations}

Since all aspects of the model configurations in Sect. 3 are identical, except for the grid on which the prescribed SSTs and ice concentrations are passed to the other model components (and therefore the atmosphere-ocean exchange computation grid), we hypothesize that the marked difference in TC climatology is induced by the coupling strategy and difference in grid resolutions. To assess the differences in simulated TCs in a controlled, deterministic manner, we utilize two identical CAM setups to complete short-term forecast simulations of observed storms. These simulations utilize the new variable-resolution capability of CAM-SE (Zarzycki et al., 2014b).

The setup is similar to that used in the previous section, but the model is configured with a variable-resolution atmospheric grid with $0.125^{\circ}(\sim 14 \mathrm{~km}$, ne240) resolution over the Atlantic Ocean. Forecast simulations are initialized with a digitally filtered atmospheric analysis from the National Centers for Environmental Prediction (NCEP) Global Data Assimilation System (GDAS). Observed SSTs on a $1^{\circ} \times 1^{\circ}$ grid are derived from the NOAA high-resolution blended analyses (Reynolds et al., 2007). The land surface is modeled by CLM 4.0 and is initialized with a state nudged to be in balance with the atmospheric initial conditions. The model setup and initialization are both thoroughly detailed in Zarzycki and Jablonowski (2015).

As in the climate simulations, the only difference between the two setups is the grid used by the data ocean and ice models. The first set of simulations uses the aforementioned displaced pole grid with an equivalent resolution of $1^{\circ}$ (ne240_gx1v6) while the second uses an ocean grid identical to the atmospheric grid with an equivalent resolution of $0.125^{\circ}$ (ne240_ne240). Since the SST and ice cover data are provided at coarser scales than the model interpolates to, any differences in the results again arise due to the differences in calculating of surface fluxes and momentum drag on the corresponding ocean grids.

After initialization, each configuration is integrated for 8 days. Figure 5 shows the $120 \mathrm{~h}$ forecasts for Hurricane Leslie in the North Atlantic Ocean from the 2012 hurricane season. The simulation was initialized at $00 \mathrm{Z}$ on $31 \mathrm{Au}-$ gust 2012, making Fig. 5 valid at 00Z on 5 September 2012. The forecast using the $1^{\circ}$ ocean grid is on the left (Fig. 5a, d), with the $0.125^{\circ}$ ocean grid in the center (Fig. 5b, e). In Fig. 5a, b, d, and e all calculations are done on the ocean grid. All fields are extracted from the atmospheric model component. The simulated intensity of Hurricane Leslie at $120 \mathrm{~h}$ (as measured by minimum sea level pressure) was 950 and $958 \mathrm{hPa}$ for the ne240_gx1v6 and ne240_ne240 configurations, respectively. Both configurations predicted a TC 

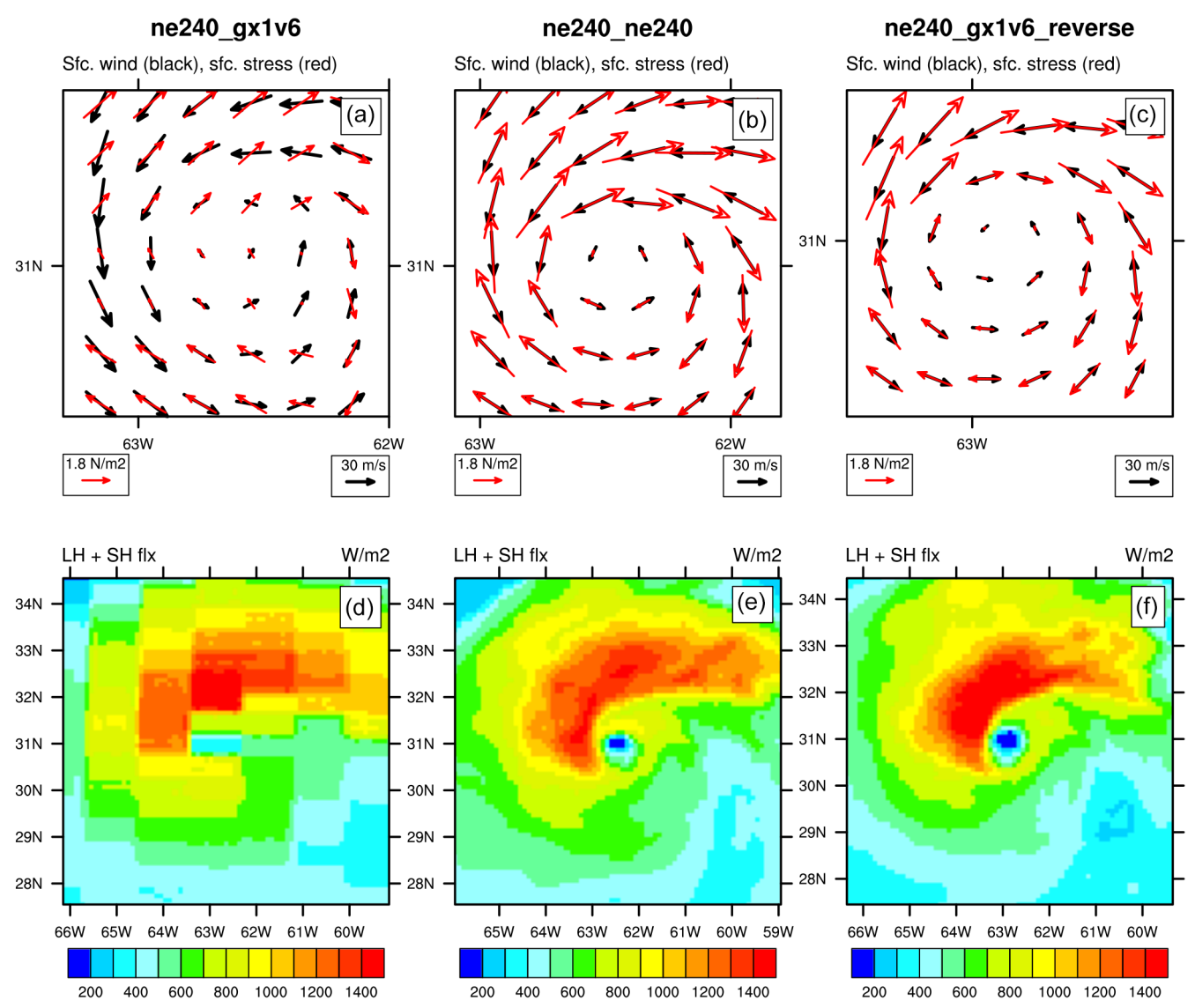

Figure 5. $120 \mathrm{~h}$ CAM-SE forecast for Hurricane Leslie, valid at 00Z on 5 September 2012. Left panels (a, d) are results from forecast using $1^{\circ}$ ocean grid in the default configuration (calculations of momentum drag and surface fluxes are carried out on the ocean grid). Center panels (b, e) show results using $0.125^{\circ}$ ocean grid. Right panels $(\mathbf{c}, \mathbf{f})$ show version of $1^{\circ}$ ocean grid where calculations are instead carried out on the finer atmospheric grid. Top panels (a-c) display instantaneous wind in the lowest model (black vectors) with corresponding lowest model level wind stress (red vectors). Lower panels (d-f) show total surface flux (latent plus sensible heat).

stronger than the observed intensity at that forecast time $(988 \mathrm{hPa})$, in broad agreement with previous work that has shown CAM5-SE produces TCs which are (on average) too intense in forecast frameworks at $0.125^{\circ}$ resolution (Zarzycki and Jablonowski, 2015). However, it should be emphasized that we are not concerned with forecast verification, but rather, the relative differences that arise due to coupling strategy despite identically initialized cases to confirm differences suggested by the analysis of the decadal simulations. Highly similar results to those highlighted here would be expected when using different historical TCs or even more idealized frameworks.

The top panels depict instantaneous lowest model level wind (black vectors) as well as the surface frictional stress vector (red). In Fig. 5a, it is readily apparent that many instances exist where the vectors are not aligned. This results from the surface stress being calculated on the coarser ocean grid. This coarser information is then used to provide stress information at the higher resolution used by the atmospheric numerics (as in Fig. 1). In Fig. 5b, the wind and stress vectors are parallel $\left(180^{\circ}\right.$ difference), indicating that the frictional drag is acting in direct opposition to the wind within the atmospheric dynamical core, which is the expected behavior from theory. The higher-resolution ocean grid preserves the resolution of the surface wind field during stress calculations. Because of this, not only are the stress vectors properly aligned with the high-resolution ocean grid, the maximum magnitudes of the stress vectors are larger at the storm's radius of maximum wind in Fig. 5b when compared against Fig. 5a.

This highlights that maxima in the stress field at the atmospheric grid cell scale are conserved with the higherresolution ocean grid, whereas these maxima are "smoothed" in the calculation where wind is first averaged to the coarser ocean grid (Fig. 5a). This is further evidenced by the fact that the integrated dot product (over a $3^{\circ} \times 3^{\circ}$ domain centered over the TC minimum surface pressure) of the two fields is approximately $20 \%$ smaller in the simulations using the $1^{\circ}$ ocean grid. Therefore, the use of the coarser ocean grid results in a misaligned, and therefore universally weaker, fric- 
tional force fed back to the atmospheric dynamics, leading to enhanced extreme wind speeds.

The cumulative surface heat (sensible plus latent) flux is shown on the bottom of Fig. 5 for the two storms at the same forecast time. It is clear that the coarser ocean grid (Fig. 5d) provides information back to the atmosphere with significantly less spatial structure than the $0.125^{\circ}$ ocean grid (Fig. 5e). While the difference in $5^{\circ} \times 5^{\circ}$ integrated heat flux is relatively small (approximately $1 \%$ ), it is clear that the spatial structure of the heat flux field is very different between the two model configurations. The pattern of surface heat and moisture fluxes underneath TCs has been shown to be critically important in intensification processes (Peng et al., 1999; Chan et al., 2001; Wang and Wu, 2004). Therefore, the choice of coupling grid may play an indirect role in storm energetics, with the $1^{\circ}$ ocean grid providing a larger, more diffuse source of surface heating to the boundary layer within the TC core.

To conclusively verify that this discrepancy arises from the choice of coupling, we complete a third simulation, which is identical to the ne240_gx1v6 simulation, except coupling calculations are carried out on the higher-resolution atmospheric grid (ne240_gx1v6_reverse) instead of the ocean. If the TC behavior in the ne240_gx1v6 configuration is due to errors arising from carrying out computations on the coarser grid in the coupling system, we expect this to be primarily alleviated by ensuring coupling is carried out on the higherresolution grid. This should result in maximum spatial resolution of the computed fields and no "loss" of information due to interpolation from fine to coarse and back to fine resolutions. Figure $5 \mathrm{c}$ and $\mathrm{f}$ show the same analysis as with the previous configurations. It is obvious that inverting the grid to ensure calculations of surface stresses and fluxes are done on the higher-resolution grid (in this case, the atmosphere) results in a solution that looks much more similar to the configuration where both atmosphere and ocean are of high resolution (Fig. 5b, e). We note that these two simulations (ne240_ne240 and ne240_gx1v6_reverse) are not fully identical due to the fact that remapping is still required in the ne240_gx1v6_reverse calculations. Examples of prominent similarities include the fact that surface stresses are stronger and aligned parallel to lowest model level wind vectors and that there is additional fine scale structure in the total surface flux field. It should be emphasized that, as discussed earlier, the resolution of the SST forcing data set is $1^{\circ}$, which provides identical spatial forcing across all configurations. If SSTs were provided at the native resolution of each ocean grid, larger differences would be expected between the ne240_ne240 and ne240_gx1v6_reverse configurations due to additional small-scale forcing (such as ocean fronts and eddies) in the ne240_ne240 experiment.

\section{Conclusions}

This paper describes biases in the distribution of atmospheric extremes which arise from choice of ocean grid and coupling strategy in CESM. Since surface stress and flux calculations are carried out on the ocean grid, running the model with a coarser ocean than atmosphere presents problems with respect to tropical cyclone (TC) climatology. In particular, surface stress vectors which are passed back to the atmospheric dynamical core following coupling are not aligned with the surface wind due to being computed on a coarser grid. This allows winds near the cores of TCs to become stronger than if the stresses were computed at the same resolution of the atmosphere. Additionally, when surface fluxes are calculated on a coarser grid, the influxes of heat and moisture to the lowest levels of the atmosphere underneath the TC are structurally different, with these quantities being more diffuse and misaligned with the maximum surface wind, in contradiction to bulk aerodynamic flux theory.

The issues outlined in the paper underscore that the choice of ocean grid when using prescribed SST and ice data to force a dynamic atmosphere is not trivial, even if the native resolution of this forcing data is relatively coarse. However, they are easy to correct for these configurations, particularly since applying coupled atmosphere-ocean calculations on the same grid is straightforward and computationally inexpensive.

More problematic adjustments may arise when coupling to a dynamical ocean model. The vast majority of coupled, dynamic simulations not only utilize differing resolutions between different model components but also different numerical techniques and grids. Therefore, remapping between components is, in many cases, an absolute necessity. The obvious recommendation to alleviate coupling inconsistencies, when it is not feasible to use identical grids, is to calculate these quantities on the finest resolution grid of the coupled system. Performing coupling in this manner ensures that information passed back to a model component has not been interpolated to a resolution coarser than the component's native resolution during the coupling process. In addition, in integrated models which allow for multiple grid options, the choice of the model component defining the grid for these calculations should not be preconfigured for all cases, but rather, determined dynamically based on the various resolutions chosen for the particular model setup.

However, we emphasize that, even when applying this suggestion, it is not clear that it is fully appropriate for coupled dynamical models to be run at highly disparate resolutions from one another, where processes interacting between components may be sufficiently nonlinear, that essentially averaging from a higher-resolution grid is not the most appropriate mechanism. Further work will be required to determine whether or not this is the case. Additionally, this strategy is not elementary when variable-resolution grids are coupled to uniform grids, particularly where the finest and coars- 
est scales of the multiresolution grid may straddle the grid scales of the uniform-resolution component. In these cases, the choice of "finer" grid in the atmosphere-ocean coupling will be different depending on the region of interest, and may require even more flexible frameworks, such as exchange grids (Balaji et al., 2006; Valcke et al., 2012).

Our results demonstrate that the mean climatology of the simulations presented here are essentially identical regardless of coupling strategy, highlighting that this impact only becomes readily apparent in the tail of the distributions of interest. However, with climate models being used more and more frequently for direct analysis of extreme events, including TCs, both in present climate and under future scenarios, this sensitivity of model-derived extremes may become more prevalent. This is especially relevant as atmospheric models continue to march forward with respect to horizontal resolution, and therefore, their ability to dynamically resolve phenomena at smaller and smaller spatial scales. Consideration of these impacts when utilizing high-resolution climate data for analysis is required and modifications to how the current generation of atmospheric models treats coupling between various earth system components in supported configurations may be necessary.

Acknowledgements. The National Center for Atmospheric Research (NCAR) is sponsored by the National Science Foundation. The authors would like to thank John E. Truesdale for assistance in performing the simulations. Resources of the Argonne Leadership Computing Facility at Argonne National Laboratory, which is supported by the Office of Science of the US Department of Energy under contract DE-AC02-06CH11357, were used for this research. An award of computer time was provided by the Innovative and Novel Computational Impact on Theory and Experiment (INCITE) program. Computing resources (ark:/85065/d7wd3xhc) were also provided by the Climate Simulation Laboratory at NCAR's Computational and Information Systems Laboratory, sponsored by the National Science Foundation and other agencies. Furthermore, this work utilizes part of the "Using Petascale Computing Capabilities to Address Climate Change Uncertainties" PRAC allocation support by the National Science Foundation ACI-1036146. This work is also part of the Blue Waters sustained-petascale computing project, which is supported by the National Science Foundation (awards OCI-0725070 and ACI-1238993) and the state of Illinois. Blue Waters is a joint effort of the University of Illinois at Urbana-Champaign and its National Center for Supercomputing Applications. Bacmeister was partially supported through the Scientific Discovery through Advanced Computing (SciDAC) program funded by US Department of Energy, Office of Science, Advanced Scientific Computing Research. Bates and Rosenbloom were supported by the Regional and Global Climate Modeling Program (RGCM) of the US Department of Energy, Office of Science (BER), Cooperative Agreement DE-FC02-97ER62402. IBTrACS data were freely obtained from the National Oceanic and Atmospheric Administration (http://www.ncdc.noaa.gov/ibtracs/). Model data from all simulations in this paper are archived and available at NCAR upon request through the authors.
Edited by: S. Valcke

\section{References}

Bacmeister, J. T., Wehner, M. F., Neale, R. B., Gettelman, A., Hannay, C., Lauritzen,, P. H., Caron, J. M., and Truesdale, J. E.: Exploratory High-Resolution Climate Simulations using the Community Atmosphere Model (CAM), J. Climate, 27, 3073-3099, doi:10.1175/JCLI-D-13-00387.1, 2014.

Balaji, V., Anderson, J., Held, I., Winton, M., Durachta, J., Malyshev, S., and Stouffer, R. J.: The Exchange Grid: a mechanism for data exchange between earth system components on independant grids, in: 2005 International Conference on Parallel Computational Fluid Dynamics, Elsevier Acadamic Press, College Park, MD, USA, 2006.

Bengtsson, L., Hodges, K. I., and Esch, M.: Tropical cyclones in a T159 resolution global climate model: comparison with observations and re-analyses, Tellus A, 59, 396-416, doi:10.1111/j.1600-0870.2007.00236.x, 2007.

Camargo, S. J.: Global and Regional Aspects of Tropical Cyclone Activity in the CMIP5 Models, J. Climate, 26, 9880-9902, doi:10.1175/JCLI-D-12-00549.1, 2013.

Chan, J. C. L., Duan, Y., and Shay, L. K.: Tropical Cyclone Intensity Change from a Simple Ocean-Atmosphere Coupled Model, J. Atmos. Sci., 58, 154-172, doi:10.1175/15200469(2001)058<0154:TCICFA>2.0.CO;2, 2001.

Craig, A. P., Vertenstein, M., and Jacob, R.: A new flexible coupler for earth system modeling developed for CCSM4 and CESM1, Int. J. High Perf. Comput. Appl., 26, 31-42, doi:10.1177/1094342011428141, 2012.

Dennis, J. M., Edwards, J., Evans, K. J., Guba, O., Lauritzen, P. H., Mirin, A. A., St-Cyr, A., Taylor, M. A., and Worley, P. H.: CAMSE: A scalable spectral element dynamical core for the Community Atmosphere Model, Int. J. High Perf. Comput. Appl., 26, 74-89, doi:10.1177/1094342011428142, 2012.

Evans, K. J., Lauritzen, P. H., Mishra, S. K., Neale, R. B., Taylor, M. A., and Tribbia, J. J.: AMIP Simulation with the CAM4 Spectral Element Dynamical Core, J. Climate, 26, 689-709, doi:10.1175/JCLI-D-11-00448.1, 2013.

Gates, W. L.: AMIP: The Atmospheric Model Intercomparison Project, B. Am. Meteorol. Soc., 73, 1962-1970, 1992.

Huffman, G. J., Adler, R. F., Bolvin, D. T., Gu, G., Nelkin, E. J., Bowman, K. P., Hong, Y., Stocker, E. F., and Wolff, D. B.: The TRMM Multisatellite Precipitation Analysis (TMPA): Quasiglobal, multiyear, combined-sensor precipitation estimates at fine scales, J. Hydrometeorol., 8, 38-55, doi:10.1175/JHM560.1, 2007.

Hurrell, J. W., Hack, J. J., Shea, D., Caron, J. M., and Rosinski, J.: A New Sea Surface Temperature and Sea Ice Boundary Dataset for the Community Atmosphere Model, J. Climate, 21, 5145-5153, doi:10.1175/2008JCLI2292.1, 2008.

Hurrell, J. W., Holland, M. M., Gent, P. R., Ghan, S., Kay, J. E., Kushner, P. J., Lamarque, J. F., Large, W. G., Lawrence, D., Lindsay, K., Lipscomb, W. H., Long, M. C., Mahowald, N., Marsh, D. R., Neale, R. B., Rasch, P., Vavrus, S., Vertenstein, M., Bader, D., Collins, W. D., Hack, J. J., Kiehl, J., and Marshall, S.: The Community Earth System Model: A Framework 
for Collaborative Research, B. Am. Meteorol. Soc., 94, 13391360, doi:10.1175/BAMS-D-12-00121.1, 2013.

Kalnay, E., Kanamitsu, M., Kistler, R., Collins, W., Deaven, D., Gandin, L., Iredell, M., Saha, S., White, G., Woollen, J., Zhu, Y., Leetmaa, A., Reynolds, R., Chelliah, M., Ebisuzaki, W., Higgins, W., Janowiak, J., Mo, K. C., Ropelewski, C., Wang, J., Jenne, R., and Joseph, D.: The NCEP/NCAR 40-Year Reanalysis Project, B. Am. Meteorol. Soc., 77, 437-471, doi:10.1175/15200477(1996)077<0437:TNYRP>2.0.CO;2, 1996.

Kim, D., Sobel, A. H., Del Genio, A. D., Chen, Y., Camargo, S. J., Yao, M.-S., Kelley, M., and Nazarenko, L.: The Tropical Subseasonal Variability Simulated in the NASA GISS General Circulation Model, J. Climate, 25, 4641-4659, doi:10.1175/JCLI-D-1100447.1, 2012.

Knapp, K. R., Kruk, M. C., Levinson, D. H., Diamond, H. J., and Neumann, C. J.: The International Best Track Archive for Climate Stewardship (IBTrACS), B. Am. Meteorol. Soc., 91, 363376, doi:10.1175/2009BAMS2755.1, 2010.

Knutson, T. R., Sirutis, J. J., Garner, S. T., Held, I. M., and Tuleya, R. E.: Simulation of the Recent Multidecadal Increase of Atlantic Hurricane Activity Using an 18-km-Grid Regional Model, B. Am. Meteorol. Soc., 88, 1549, doi:10.1175/BAMS-88-10-1549, 2007.

Knutson, T. R., McBride, J. L., Chan, J., Emanuel, K., Holland, G., Landsea, C., Held, I., Kossin, J. P., Srivastava, A. K., and Sugi, M.: Tropical cyclones and climate change, Nat. Geosci., 3, 157163, doi:10.1038/ngeo779, 2010.

Lim, Y.-K., Schubert, S. D., Reale, O., Lee, M.-I., Molod, A. M., and Suarez, M. J.: Sensitivity of Tropical Cyclones to Parameterized Convection in the NASA GEOS-5 Model, J. Climate, 28, 551-573, doi:10.1175/JCLI-D-14-00104.1, 2014.

Manganello, J. V., Hodges, K. I., Kinter, J. L., Cash, B. A., Marx, L., Jung, T., Achuthavarier, D., Adams, J. M., Altshuler, E. L., Huang, B., Jin, E. K., Stan, C., Towers, P., and Wedi, N.: Tropical Cyclone Climatology in a 10-km Global Atmospheric GCM: Toward Weather-Resolving Climate Modeling, J. Climate, 25, 3867-3893, doi:10.1175/JCLI-D-11-00346.1, 2012.

Murakami, H., Wang, Y., Yoshimura, H., Mizuta, R., Sugi, M., Shindo, E., Adachi, Y., Yukimoto, S., Hosaka, M., Kusunoki, S., Ose, T., and Kitoh, A.: Future Changes in Tropical Cyclone Activity Projected by the New High-Resolution MRI-AGCM, J. Climate, 25, 3237-3260, doi:10.1175/JCLI-D-11-00415.1, 2012.

Neale, R. B., Chen, C.-C., Gettelman, A., Lauritzen, P. H., Park, S., Williamson, D. L., Conley, A. J., Garcia, R., Kinnison, D., Lamarque, J.-F., Marsh, D., Mills, M., Smith, A. K., Tilmes, S., Vitt, F., Cameron-Smith, P., Collins, W. D., Iacono, M. J., Easter, R. C., Liu, X., Ghan, S. J., Rasch, P. J., and Taylor, M. A.: Description of the NCAR Community Atmosphere Model (CAM 5.0), NCAR Technical Note NCAR/TN-486+STR, National Center for Atmospheric Research, Boulder, Colorado, 2012.

Oleson, K., Lawrence, D., Bonan, G., Flanner, M., Kluzek, E., Lawrence, P., Levis, S., Swenson, S., Thornton, P., Dai, A., Decker, M., Dickinson, R., Feddema, J., Heald, C., Hoffman, F., Lamarque, J., Mahowald, N., Niu, G., Qian, T., Randerson, J., Running, S., Sakaguchi, K., Slater, A., Stockli, R., Wang, A., Yang, Z., Zeng, X., and Zeng, X.: Technical Description of version 4.0 of the Community Land Model (CLM), NCAR Techni- cal Note NCAR/TN-478+STR, National Center for Atmospheric Research, Boulder, Colorado, doi:10.5065/D6FB50WZ, 2010.

Oouchi, K., Yoshimura, J., Yoshimura, H., Mizuta, R., Kusunoki, S., and Noda, A.: Tropical Cyclone Climatology in a GlobalWarming Climate as Simulated in a $20 \mathrm{~km}-$ Mesh Global Atmospheric Model: Frequency and Wind Intensity Analyses, J. Meteorol. Soc. Jpn., 84, 259-276, 2006.

Peng, M. S., Jeng, B.-F., and Williams, R. T.: A Numerical Study on Tropical Cyclone Intensification. Part I: Beta Effect and Mean Flow Effect, J. Atmos. Sci., 56, 1404-1423, doi:10.1175/15200469(1999)056<1404:ANSOTC>2.0.CO;2, 1999.

Reed, K. A. and Jablonowski, C.: Impact of physical parameterizations on idealized tropical cyclones in the Community Atmosphere Model, Geophys. Res. Lett., 38, L04805, doi:10.1029/2010GL046297, 2011a.

Reed, K. A. and Jablonowski, C.: Assessing the Uncertainty of Tropical Cyclone Simulations in NCAR's Community Atmosphere Model, J. Adv. Model. Earth Syst., 3, M08002, doi:10.1029/2011MS000076, 2011 b.

Reed, K. A. and Jablonowski, C.: Idealized tropical cyclone simulations of intermediate complexity: A test case for AGCMs, J. Adv. Model. Earth Syst., 4, M04001, doi:10.1029/2011MS000099, 2012.

Reed, K. A., Bacmeister, J. T., Wehner, Rosenbloom, N. A., F., M., Bates, S. C., Lauritzen, P. H., Truesdale, J. T., and Hannay, C.: Impact of the dynamical core on the direct simulation of tropical cyclones in a high-resolution global model, Geophys. Res. Lett., 42, GL063974, doi:10.1002/2015GL063974, 2015.

Reynolds, R. W., Smith, T. M., Liu, C., Chelton, D. B., Casey, K. S., and Schlax, M. G.: Daily High-Resolution-Blended Analyses for Sea Surface Temperature, J. Climate, 20, 5473-5496, doi:10.1175/2007JCLI1824.1, 2007.

Rienecker, M. M., Suarez, M. J., Gelaro, R., Todling, R., Bacmeister, J., Liu, E., Bosilovich, M. G., Schubert, S. D., Takacs, L., Kim, G.-K., Bloom, S., Chen, J., Collins, D., Conaty, A., da Silva, A., Gu, W., Joiner, J., Koster, R. D., Lucchesi, R., Molod, A., Owens, T., Pawson, S., Pegion, P., Redder, C. R., Reichle, R., Robertson, F. R., Ruddick, A. G., Sienkiewicz, M., and Woollen, J.: MERRA: NASA's Modern-Era Retrospective Analysis for Research and Applications, J. Climate, 24, 3624-3648, doi:10.1175/JCLI-D-11-00015.1, 2011.

Satoh, M., Oouchi, K., Nasuno, T., Taniguchi, H., Yamada, Y., Tomita, H., Kodama, C., Kinter, J., Achuthavarier, D., Manganello, J., Cash, B., Jung, T., Palmer, T., and Wedi, N.: The Intra-Seasonal Oscillation and its control of tropical cyclones simulated by high-resolution global atmospheric models, Clim. Dynam., 39, 2185-2206, doi:10.1007/s00382-011-1235-6, 2012.

Simpson, R. H.: The Hurricane Disaster - Potential Scale, Weatherwise, 27, 169-186, doi:10.1080/00431672.1974.9931702, 1974.

Strachan, J., Vidale, P. L., Hodges, K., Roberts, M., and Demory, M.-E.: Investigating Global Tropical Cyclone Activity with a Hierarchy of AGCMs: The Role of Model Resolution, J. Climate, 26, 133-152, doi:10.1175/JCLI-D-12-00012.1, 2013.

Taylor, K. E.: Summarizing multiple aspects of model performance in a single diagram, J. Geophys. Res.-Atmos, 106, 7183-7192, doi:10.1029/2000JD900719, 2001.

Taylor, M., Tribbia, J., and Iskandarani, M.: The Spectral Element Method for the Shallow Water Equations on the Sphere, J. Comput. Phys., 130, 92-108, 1997. 
Taylor, M. A.: Conservation of Mass and Energy for the Moist Atmospheric Primitive Equations on Unstructured Grids, in: Numerical Techniques for Global Atmospheric Models, edited by: Lauritzen, P. H., Jablonowski, C., Taylor, M. A., and Nair, R. D., Vol. 80 of Lecture Notes in Computational Science and Engineering, Springer, 357-380, 2011.

Taylor, M. A. and Fournier, A.: A compatible and conservative spectral element method on unstructured grids, J. Comput. Phys., 229, 5879-5895, 2010.

Thomas, S. and Loft, R.: The NCAR Spectral Element Climate Dynamical Core: Semi-Implicit Eulerian Formulation, J. Sci. Comput., 25, 307-322, doi:10.1007/s10915-004-4646-2, 2005.

Valcke, S., Balaji, V., Craig, A., DeLuca, C., Dunlap, R., Ford, R. W., Jacob, R., Larson, J., O'Kuinghttons, R., Riley, G. D., and Vertenstein, M.: Coupling technologies for Earth System Modelling, Geosci. Model Dev., 5, 1589-1596, doi:10.5194/gmd-51589-2012, 2012.

Vitart, F., Anderson, J. L., and Stern, W. F.: Simulation of interannual variability of tropical storm frequency in an ensemble of GCM integrations, J. Climate, 10, 745-760, 1997.

Walsh, K. J. E., Camargo, S. J., Vecchi, G. A., Daloz, A. S., Elsner, J., Emanuel, K., Horn, M., Lim, Y.-K., Roberts, M., Patricola, C., Scoccimarro, E., Sobel, A. H., Strazzo, S., Villarini, G., Wehner, M., Zhao, M., Kossin, J. P., LaRow, T., Oouchi, K., Schubert, S., Wang, H., Bacmeister, J., Chang, P., Chauvin, F., Jablonowski, C., Kumar, A., Murakami, H., Ose, T., Reed, K. A., Saravanan, R., Yamada, Y., Zarzycki, C. M., Vidale, P. L., Jonas, J. A., and Henderson, N.: Hurricanes and climate: the U.S. CLIVAR working group on hurricanes, B. Am. Meteorol. Soc., 96, 997-1017, doi:10.1175/BAMS-D-13-00242.1, 2015.

Wang, Y. and Wu, C.-C.: Current understanding of tropical cyclone structure and intensity changes-a review, Meteorol. Atmos. Phys., 87, 257-278, 2004.

Wehner, M. F., Reed, K. A., Li, F., Prabhat, Bacmeister, J., Chen, C.-T., Paciorek, C., Gleckler, P. J., Sperber, K. R., Collins, W. D., Gettelman, A., and Jablonowski, C.: The effect of horizontal resolution on simulation quality in the Community Atmospheric Model, CAM5.1, J. Adv. Model. Earth Syst., 6, 980-997, doi:10.1002/2013MS000276, 2014.
Wehner, M. F., Prabhat, Reed, K. A., Stone, D., Collins, W. D., and Bacmeister, J. T.: Resolution dependence of future tropical cyclone projections of CAM5.1 in the US CLIVAR Hurricane Working Group idealized configurations, J. Climate, 28, 39053925, doi:10.1175/JCLI-D-14-00311.1, 2015.

Zarzycki, C. M. and Jablonowski, C.: A multidecadal simulation of Atlantic tropical cyclones using a variable-resolution global atmospheric general circulation model, J. Adv. Model. Earth Syst., 6, 805-828, doi:10.1002/2014MS000352, 2014.

Zarzycki, C. M. and Jablonowski, C.: Experimental tropical cyclone forecasts using a variable-resolution global model, Mon. Weather Rev., 143, 4012-4037, doi:10.1175/MWR-D-15-0159.1, 2015.

Zarzycki, C. M., Jablonowski, C., and Taylor, M. A.: Using Variable Resolution Meshes to Model Tropical Cyclones in the Community Atmosphere Model, Mon. Weather Rev., 142, 1221-1239, doi:10.1175/MWR-D-13-00179.1, 2014a.

Zarzycki, C. M., Levy, M. N., Jablonowski, C., Overfelt, J. R., Taylor, M. A., and Ullrich, P. A.: Aquaplanet Experiments Using CAM's Variable-Resolution Dynamical Core, J. Climate, 27, 5481-5503, doi:10.1175/JCLI-D-14-00004.1, 2014b.

Zarzycki, C. M., Jablonowski, C., Thatcher, D. R., and Taylor, M. A.: Effects of localized grid refinement on the general circulation and climatology in the Community Atmosphere Model, J. Climate, 28, 2777-2803, doi:10.1175/JCLI-D-14-00599.1, 2015.

Zhao, M., Held, I. M., Lin, S. J., and Vecchi, G. A.: Simulations of Global Hurricane Climatology, Interannual Variability, and Response to Global Warming Using a 50-km Resolution GCM, J. Climate, 22, 6653-6678, 2009.

Zhao, M., Held, I. M., and Lin, S.-J.: Some Counterintuitive Dependencies of Tropical Cyclone Frequency on Parameters in a GCM, J. Atmos. Sci., 69, 2272-2283, doi:10.1175/JAS-D-11-0238.1, 2012. 